\title{
Movimento social africano de Fidjus Dibideras de Guiné-Bissau em espaços universitários
}

\author{
Ricardino Jacinto Dumas Teixeira \\ SANDRA TRICIA BATICAM
}

RESUMO: O artigo apresenta distintas produções artístico-culturais de fidjus dibideras, na Guiné-Bissau e em suas diásporas, como expressão de um movimento social africano em espaços universitários. A análise foi elaborada em três momentos: no primeiro, discute-se a emergência da noção de bidera, anterior à colonização portuguesa; no segundo, apresentam-se as transformações que ocorreram na Guiné-Bissau, conectadas transnacionalmente; e, por fim, formulase o conceito de fidjus dibideras, que suscita um novo olhar analítico no estudo de produções culturais dos seus agentes.

PALAVRAS-CHAVE:

Cultura.

Movimento Social. Guiné-Bissau.

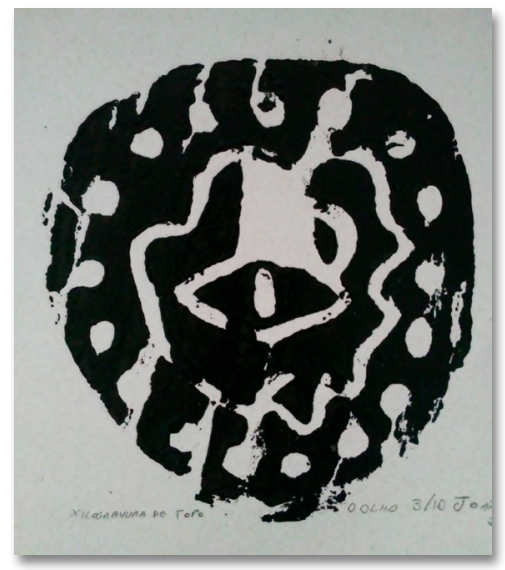

\section{African social movement of Guinea Fidjus Dibideras in university spaces}

\section{Ricardino Jacinto Dumas TeIXeIRa}

Professor-adjunto de Sociologia na Universidade de Integração Internacional da Lusofonia Afro-Brasleira (UNILAB) e pesquisador do Observatório das Nacionalidades, Brasil.

E-mail: ricardino@unilab.edu.br

\section{SANDRA Tricia Baticam}

Bacharel em Humanidades pela Universidade de Integração Internacional da Lusofonia AfroBrasleira (UNILAB).

E-mail: sandratricia@gmail.com
ABSTRACT: The article presents different artistic-cultural productions of fidjus dibideras in Guinea-Bissau and its diasporas, as an expression of an African social movement in university spaces. The analysis was elaborated in three moments: in the first, we discuss the emergence of the notion of bidera, prior to the Portuguese colonization; in the second, the transformations that occurred in Guinea, connected transnationally, and, finally, the concept of fidjus dibideras is formulated, giving rise to a new analytical look in the study of cultural productions of its agents.

KEYWORDS: Culture. Social Movement. Guinea Bissau.

RECEBIDO: 06/07/2020

APROVADO: 03/09/2020

Tensões Mundiais | 91 


\section{Introdução'}

Na última década, vivenciamos, na Guiné-Bissau² e nas suas diferentes diásporas, mudanças estruturais - socioculturais, socioeducacionais e sociopolíticas - que se refletem na produção de um conhecimento crítico, autônomo e que pode ser concebido particularmente na literatura produzida no âmbito local e no contexto diaspórico. Esse conhecimento encontra-se em diálogo incessante com a literatura-mundo e, em diversas perspectivas e sentidos, nos textos literários.

Nesse processo societal guineense de mudança, a presença do movimento social africano de fidjus dibideras (filhos de mulheres que trabalham no mercado informal desde a época anterior à colonização), urbanos e rurais, assume um papel importante, uma vez que podemos, aqui, encarar seu contexto de produções artístico-culturais como uma forma inovadora e fundamental, que suscita um novo olhar analítico, produzindo um conhecimento crítico à sociedade guineense, no qual as diferentes diásporas também se encontram.

Para compreender os sentidos que atribuímos a nós mesmos quando utilizamos a expressão fidjus dibideras em sua emergência distinta, relacional e complementar na sociedade guineense, faz-se necessário que situemos inicialmente o desenvolvimento do conceito de bidera. Tal conceito tem sido frequentemente questionado, deturpado ou não devidamente entendido, ou ainda entendido a partir de outros significados distintos do nosso. Em seguida, é necessário apresentarmos as transformações que ocorreram na sociedade e nas diásporas guineenses, as quais geraram as necessárias condições para a emergência e a afirmação conceitual e cívica no campo da produção intelectual e cultural dos fidjus dibideras.

1 Agradecemos aos pareceristas pela leitura crítica do artigo.

2 Guiné-Bissau está localizada no continente africano. Seu território continental faz fronteira ao norte com o Senegal e ao sudeste com a República da Guiné, também denominada Guiné Conacri, e ao sul e ao oeste com o Oceano Atlântico. Administrativamente, o país é subdividido em oito regiões, trinta e seis setores, além do setor autônomo de Bissau e o arquipélago dos Bijagós, este composto por dezenas de ilhas e civilizações (cf. Augel, 2007). 


\section{Conceito de bidera}

Identificamos, no decorrer da formação societal e literária guineense, quatro momentos distintos e complementares, para a significação da expressão bidera: (a) o período anterior e posterior à colonização; (b) o momento de unidade e luta de libertação comum entre a Guiné-Bissau e Cabo Verde (dirigido pelo intelectual revolucionário, Amílcar Cabral); (c) o período de ruptura da unidade, no regime de partido único; (d) e o período atual, a partir da democratização, em que acrescentamos um novo sentido ao conceito de bidera com a designação fidjus dibideras. Neste sentido, a nova designação ganha peso e visibilidade no mundo literário, cívico, artístico e acadêmico, bem como no campo de produção de um conhecimento de Guiné-Bissau no mundo, apontando as suas caraterísticas e especificidades que requerem um olhar multidimensional e relacional distinto na atualidade.

Uma das primeiras conceitualizações sobre bidera, em conformidade aos escritos de Antonio Carreira (1983), é entendida como um conjunto de grupos urbanos e rurais de mulheres de condição social de origem popular, que exercem função social nos mercados públicos. Nos finais do século XVIII e princípios do século XIX, na "Guiné Portuguesa", a função social dessas mulheres carregava os aspectos históricos e socioeconômicos, marcando um longo período de sociabilidade local, interétnica, multicultural, de uma comunidade imaginada (ANDERSON, 2008), anterior e posterior à colonização portuguesa em África.

O investigador guineense do Instituto Nacional de Estudos e Pesquisas (INEP) Samba Tenem Camará (2011) descreveu, de forma sintética, empírica e atual, o funcionamento e a organização dos mercados de Lumo à luz da dinâmica comercial e cultural do mercado de Mafanco, região Leste de Gabu, em que as mulheres, em sua maioria, buscam a sobrevivência cotidiana e também a construção de laços de sociabilidade individual e coletiva "à guineense". Esse trabalho ilustra a emergência de feiras Lumos no comércio popular guineense, com a subjacente ideia de bideras.

Essas dinâmicas societais, presentes em tempos mais remotos, se consolidaram após a independência e, posteriormente, se articularam nos campos da literatura vanguardista e da música 
revolucionária para o processo de reconstrução nacional (de uma nação forjada, para parafrasear Amílcar Cabral, na arma da teoria de luta de libertação), concluída com a proclamação da independência nacional entre 1973 e 1974.

As produções artístico-culturais de jovens fidjus dibideras, oriundos de famílias camponesas rurais ou das zonas urbanas mais populares, constituíram-se, em termos sociológicos, contingente populacional à causa da independência do movimento de libertação. Posteriormente, houve um desencantamento dos jovens guineenses pelas promessas não cumpridas e por crises de representatividade da Terra Mãe, conforme explicitado por escritores como Bidera-Pátria (AUGEL, 2007). É também nesse contexto após-independência que a Mãe Guiné era simbolizada pelo seu corpo maltratado, em textos noticiosos, poéticos, cantigas de grupos de mandjuandades, literaturas, cinemas, artes plásticas, artefatos, produção intelectual, adivinhas e pinturas.

O ambiente literário da época fez emergir um conjunto de linguagens e textos marcados pelo desejo de reforçar o discurso da unidade e luta entre a Guiné-Bissau e Cabo Verde. Na independência binacional (de desenvolvimento voltado ao progresso), esse discurso foi assumido principalmente, mas não exclusivamente, pela geração literária chamada meninos de pindjiguite, ${ }^{3}$ no contexto pós-revolução política.

Os textos literários foram produzidos majoritariamente por estudantes e ex-estudantes que tiveram acesso ao ensino no então Liceu Nacional Honório Pereira Barreto, em um contexto marcado pela herança negativa do colonialismo. Essa geração literária dividia-se entre "civilizados" e "indígenas". Os primeiros eram urbanizados na sua maioria, que gozavam de um estatuto "especial" e serviram durante muito tempo de intermediários entre portugueses e guineenses; já os segundos eram grupos éticos, que resistiam ao domínio colonial e se encontravam além do alcance jurídico e administrativo das autoridades locais.

A literatura serviu de base para uma expressão libertária dos jovens que foram confrontados com decepções com os "novos donos do poder", em que a língua portuguesa e krioula, acrescidas

3 O cais de Pindjiguite simboliza a resistência dos marinheiros guineenses contra a presença colonial. 
de línguas das sociedades étnicas guineense, serviram de veículo comunicativo para o tchon, com a Terra Mãe-Pátria-Bidera. A figura de Amílcar Cabral, Sol Maior, Lantindan, e de combatentes guineenses-caboverdianos, eram sonantes e dominavam no repertório literário, pelo papel que assumiram no processo de independência.

Após a independência, nos anos 1980, as atividades destinadas às bideras sofreram alterações, principalmente com a construção de cooperativas agrícolas como forma de tentar romper com o legado negativo do modo de produção, consumo, distribuição e comercialização capitalista do regime colonial, considerado nocivo. A partir de então, houve a melhoria do modo de produção "cooperativista" para o aumento dos ganhos dos produtores rurais e o controle sobre as atividades produtivas de consumo interno. Tal política serviu de base para o projeto inicial de industrialização do primeiro governo guineense-caboverdiano pós-independência de Luís Cabral (meio-irmão de Amílcar Cabral pela parte paterna), mas que não teve continuidade na promoção de mudanças estruturais. Isso deveu-se ao fim do apoio dos países do "socialismo real", decorrente da crise econômica global e que trouxe implicações profundas que culminaram no golpe de Estado de 1980, solapando a política de "unidade" entre a Guiné-Bissau e Cabo Verde. O golpe foi liderado pelo general guineense João Bernardo Vieira, combatente do movimento de libertação.

Paralelo ao discurso cooperativo, especialmente para os pequenos produtores em que se salientou o papel da agricultura, do trabalho produtivo, do armazém do povo, da revolução, da formação militante, do homem novo e da unidade, houve uma forte centralização do partido único oficioso e a negação da liberdade e dos direitos básicos, como parte da política de Estado sob a direção do partido único.

O desejo de reconstrução nacional prometido pelo Estado pós-colonial revolucionário e que marcou uma geração de jovens escritores guineenses em combatentes dos anos 1950 e 1960, agrupados em torno da "juventude cabralista" do partido da Zona Zero, ${ }^{4}$

4 A zona zero, nos arredores da capital (Bissau), era o espaço no qual ocorriam as atividades de mobilização popular, geralmente de jovens urbanos do Liceu. 
não teve os resultados esperados, seja pelo discurso da nova classe dirigente, seja em termos da prática política governativa. Foi neste contexto que houve um aumento de grupos de mulheres bideras e homens bideros, denominados na produção literária em kriolo por Mãe Guiné, Poilão $0^{5}$, Firkidja, que impactou vozes e versos de intelectuais e artistas guineenses. Esses intelectuais e artistas expressavam as suas emoções individuais e anseios nacionais que serviram de bases sociológicas e mentais para a formatação de uma geração marcada pelos acontecimentos de sua época. Este é o contexto em que a língua kriola guineense, língua nacional, foi retomada principalmente através de José Carlos Schwarz, considerado criador da identidade musical, poética e literária moderna guineense (AUGEL, 2007).

O Estado pós-colonial em África (e guineense, em particular) teve os seus primeiros passos em um momento marcado pelas políticas macroeconômicas liberais, acompanhadas de ajustamentos estruturais impostos ao Estado pelo Consenso de Washington de 1989, pelo Fundo Monetário Internacional (FMI) e pelo Banco Mundial (BM). O período também foi marcado pelo gerenciamento econômico internacional segundo o Sistema Bretton Woods, gerando mudanças globais significativas, no campo socioeconômico e político (TEIXEIRA, 2015; 2019).

Nos anos de 1980 a 1990, com o redirecionamento do eixo de desenvolvimento econômico para os processos de liberalização em África, foram promovidas reformas que frustraram as expectativas, criadas em volta da independência na manutenção da autonomia e da soberania. Para fazer face ao alto nível de desemprego, por exemplo, o Estado, confrontado com a nova realidade, induziu à informalização do mercado, mantida na atualidade pela marginalização econômica das mulheres bideras e agricultores.

Diferentes estudos mostraram que a emergência de ensino superior na Guiné-Bissau foi tardia, tendo seu momento decisivo com o surgimento da Faculdade de Medicina, criada em 1986 (FURTADO, 2005; SUCUMA, 2013; SANI; OLIVEIRA, 2014). Todavia, como normalmente acontece em outros lugares, a Faculdade de

5 Os termos Poilão (uma árvore) e Firkidja (uma protetora) simbolizam uma mulher guineense. 
Medicina não dispunha de recursos humanos suficientes, razão pela qual contava com a cooperação técnica e o apoio financeiro e educacional da República Popular da China, da Cuba, da Rússia, da Holanda e da própria Organização Mundial de Saúde (OMS) como coordenador dos esforços dos estados nacionais em termos da saúde global. A tal política de apoio ao sistema nacional de saúde guineense não teve continuidade sistemática, sobretudo devido à constante onda de crises dos anos 1980. Com o fim dos recursos técnicos e humanos vindos do antigo bloco soviético, o país precisou iniciar o seu projeto de construção de faculdades e escolas técnicas.

Em 1985, o antigo Destacamento Vanguarda Tchico Té, criado no regime de partido único oficioso, foi transformado em Escola Normal Superior de Formação de Professores de ensino básico e secundário, em algumas regiões do país. Foi criada, na capital político-administrativo, a Faculdade de Direito de Bissau (em 1990) com o objetivo de reforçar as capacidades do sistema jurídico e reforçar o acesso da população à justiça. As duas instituições de ensino superior, desde suas fundações, contaram com a cooperação portuguesa, centrada no ensino, na acessória técnica e na formação de professores para o mercado de trabalho do funcionalismo público e privado do país. As chances de fidjus dibideras entrarem em uma instituição de ensino superior aumentou, mas continuavam insuficientes os cursos superiores existentes no país, tanto nas instituições públicas, quanto nos estabelecimentos privados de ensino superior.

Só em 1999, treze anos após a fundação da Faculdade de Medicina, surgiu, em Bissau, a primeira instituição pública universitária, a Universidade Amílcar Cabral (UAC), assim denominada em homenagem ao líder fundador da nacionalidade guineense e cabo-verdiana. Em seu projeto inicial, a UAC ministraria cursos superiores, politécnicos e profissionalizantes, podendo expandir para graus de bacharelado e doutorado. Assim, todas as instituições de ensino superior do país ficariam sob a tutela do Estado guineense que, em termos constitucionais, deve assegurar à criança e ao adolescente o acesso à formação básica, técnica e superior. 
Se até 1999 o acesso ao ensino superior era monopólio de instituições estatais, com o surgimento da Universidade Colinas de Boé (UCB) em 2013, ocorreu abertura do mercado do ensino superior para o setor privado na Guiné-Bissau. ${ }^{6}$ A UCB surgiu em homenagem ao local no qual se proclamou a independência unilateral da República da Guiné-Bissau.

Em 2008, o governo autorizou a criação da Universidade Lusófona da Guiné (ULG), sob a administração da Universidade Lusófona de Humanidades e Tecnologia de Lisboa. Já em 2010, surgiu a Universidade Jean Piaget da Guiné Bissau com o objetivo de responder as inspirações de jovens guineenses e de satisfazer as exigências do mercado de trabalho. Trata-se, portanto, de um momento novo distinto daquele em os guineenses dependiam de instituições públicas de ensino superior na Guiné-Bissau. ${ }^{7}$

A partir desse novo contexto educacional pluralista, em que se formaram os fidjus dibideras, criaram-se as bases intelectuais para o processo da produção de novos significados literários, musicais, artísticos e poéticos, seja no âmbito local, seja no contexto da diáspora acadêmica, com a cooperação internacional de ensino superior para além do local em que se situa a Universidade da Integração Internacional da Lusofonia Afro-Brasileira (UNILAB), como espaço de transformação social e produção cultural protagonizado pelo movimento social dos fidjus dibideras guineenses.

\section{Um novo momento de fidjus dibideras}

As políticas de ajustes macroeconômicos patrocinados pelo BM e pelo FMI, no contexto dos anos 1990, adicionaram problemas educacionais e crises sociais comuns ao Brasil e aos países da África, historicamente não resolvidos, com realce no acesso ao sistema do ensino superior. A UNILAB, fundada em 2008, apareceu como uma resposta do governo brasileiro para repensar

6 A UAC foi criada pelo guineense João José Silva Monteiro, ex-ministro da Educação e dos Negócios Estrangeiros.

7 Em nível continental, surgiu, em 17 de maio de 2016, a The African Virtual University (AVU), uma rede de ensino superior em 21 países africanos, com o apoio do Banco Africano de Desenvolvimento (BAD), através da União Africana (UA). 
seu sistema de ensino superior, até então restrito a certos grupos sociais, mas também como instrumento da chamada "política solidária" de cooperação internacional de ensino superior, que ganhou prioridade na década de 1990 e se acentuou nos anos 2000, nos governos dos ex-presidentes Luís Inácio Lula da Silva (2003 - 2011) e Dilma Rousseff (2011 - 2016).

A UNILAB, dentro dos parâmetros do seu Estatuto em vigência, se fundamentou em quatro eixos prioritários de atuação universitária, nomeadamente a solidariedade do Sul, a interiorização, a democratização e a internacionalização. Sua criação foi uma política deliberada do governo brasileiro, um ator importante da cooperação, mas não o único. Houve a presença de outros agentes, sobretudo de estudantes do continente africano no Brasil, denominado por nós de fidjus dibideras, historicamente excluídos no acesso ao ensino superior em seus países de origem.

No Brasil, especialmente a UNILAB passou a ser o locus de estudantes africano-guineenses, fidjus dibideras, no âmbito da chamada "cooperação Sul-Sul" ou da inclusão da História da África no currículo escolar (lei 10.639/03). Nossa intenção visa mostrar que a expansão de ensino superior no país e nas diásporas criam novas condições de possibilidade, novos conceitos, novos sujeitos históricos, em um contexto educacional marcado pela transformação social das estruturas de mentalidades, através do pensamento e da criatividade dos fidjus dibideras na produção de saberes.

Em síntese, encontramos quatro características constitutivas em relação ao conceito de bidera, apontadas anteriormente: a primeira caraterística ficou marcada pelo mundo de trabalho físico - isto é, a falta de estruturação do mercado local e nacional, o que aponta claramente para o modo de trabalho informal, a pobreza e a marginalização de um grupo social majoritário feminino da sociedade guineense. Estes são elementos constitutivos presentes nos indicadores oficiais do Estado e das agências internacionais da ONU sobre o trabalho familiar e a informalização da economia em geral.

A segunda caraterística, por sua vez, tem a ver com a pressão social e familiar que a ausência da educação escolar exerce sobre a maioria da população feminina guineense, decorrente, mas não exclusivamente, da ocupação doméstica imposta por homens à 
sobrevivência familiar, assumida maioritariamente por mulheres, em diversos setores da vida societal.

A terceira caraterística, em sintonia com as duas primeiras, realça a degradação dos ideais da independência, em decorrência da desconstrução da estrutura social, inclusive, de infraestruturas e estruturas consideradas fundamentais que foram herdadas da colonização pelo novo regime.

A quarta caraterística, sob o viés da nossa perspectiva conceitual, refere-se à expansão de ensino superior na Guiné-Bissau e em suas diferentes diásporas, em que a UNILAB e o Brasil se destacam como locomotiva da cooperação internacional de ensino superior com África e Guiné Bissau, em que se situa a expressiva produção cultural de fidjus de mulheres bideras.

É dentro desse conjunto de acontecimentos e perspectivas que o conceito de bidera é visto na literatura sobre a sociedade guineense, marcada inicialmente pela marginalização e pobreza e que determinou o seu sentido social e sua função no mundo do trabalho. Resta agora apontarmos, finalmente, outro significado ao conceito formulado de fidjus dibideras, em oposição relacional ao conceito de bideras.

\section{Conceito de fidju dibidera}

A situação da marginalização societal das mães bideras, Mãe Guiné, em nível do mercado local e nacional de comércio do qual dependem para sobreviver, gerou concomitantemente uma situação nova, marcada pela luta das bideras pelo acesso à educação escolar dos fidjus dibideras, na Guiné Bissau e em suas diferentes diásporas.

O acesso à educação, infelizmente não assumido ou assumido seletivamente pelo Estado guineense, passou a fazer parte de um repertório vital de ações de mudança sociocultural de fidjus dibideras. É um momento novo, um contexto novo, com sentido novo e novos atores, cujo significado remete para a negação do fatalismo, do assistencialismo, do camaradismo, do comodismo e do vitimismo. Nesse sentido, colocamos uma questão distintiva ao conceito de fidjus dibideras que, para a nossa definição, nos parece fundamental responder: qual é a visão que os fidjus dibideras têm 
do mundo? Como essa visão se articula com os problemas globais, nacionais e locais? Em que medida esse movimento geracional potencializa transformações?

De acordo com a sua posição societal, a geração de fidjus dibideras é marcada pela busca de autonomia e da liberdade acadêmica, bem como pela construção intelectual de um conhecimento crítico de Guiné-Bissau, em diálogo com tudo aquilo que a humanidade produziu em termos de saberes, filosofias, artes, literaturas, ciências e tecnologias.

A presença propositiva de fidjus dibideras na UNILAB teve um papel importante na busca de novas saídas para transformações sociais atuais. Um exemplo disso acontece no âmbito das produções literárias, dos grupos musicais, dos grupos de teatro e da produção científica. Outras gerações foram marcadas por tais ideias, mas de forma menos intensa, mais residual, quando comparadas com a geração de fidjus dibideras. Realça-se, aqui, um contexto marcado pelo pluralismo e pela democratização e ampliação do acesso ao ensino superior em todos os seus aspectos e níveis. ${ }^{8}$

Os fidjus dibideras se definem como um movimento intelectual e acadêmico com potencialidade transformadora, marcada por uma visão universalista que eles têm do mundo e principalmente por uma trajetória comum de vida e lutas renhidas, enquanto grupo, enquanto agentes potenciais de mudanças na Guiné-Bissau e nas diásporas guineenses; um grupo de novas possibilidades, companhias e solidariedades, de uma vida diferente daquela que teve a maioria das bideras, nossas mães.

A marginalização a que as bideras foram submetidas no acesso aos bens socioculturais e a efetivação dos direitos a ter direitos fizeram dos fidjus dibideras, desde cedo, portadores potenciais de uma ética de estudo e de trabalho duro, sem complexos de superioridade ou inferioridade, potencializando uma nova história, um recomeço efetivado através de reconhecimento crítico da cultura e da literatura. Na atualidade, fica claro que a presença de fidjus dibideras, na Guiné Bissau e em suas diferentes diásporas em que estamos inseridos, não se restringe ao campo econômico do mundo de trabalho familiar, ao setor agrícola e ao comércio informal para a

8 Firkidja di no kampada (2019). 
sobrevivência. Suas capacidades abrangem a esfera literária, política, partidária, administrativa, estética, cívica e tecnológica, não só como ocorreu com outras gerações. Agora essa abrangência se dá de forma mais intensa, porque, se conjugado, existem situações novas não restritas à pobreza, ao autoritarismo oficioso e à vida de marginalização social. Por mais que se possa questionar ou não se queira admitir, não é possível negar as transformações geradas pelo mundo globalizado, competitivo e também excludente, no qual a nossa geração está inserida como parte integrante do mundo.

Não obstante a resiliência, há riscos geracionais de fidjus dibideras, de natureza diversa e extremante viciosa. Entre os principais, nos parecem presentes as armadilhas do entusiasmo, do populismo, do amiguíssimo, do consumismo, do partidarismo, de djitu ka tem (não tem jeito), de tchonalmente (herança negativa da tradição), de uma sociedade controlada e manipulada ainda por garandis (os mais velhos), que se encontram atrelados ao sistema político (Estado e partidos). Pois, muitos de nós ainda cultivamos e acreditamos que quem não obedece às "regras dos mais velhos" não obterá sucesso e reconhecimento de "homens e mulheres grandes", que atuam como promotores de jovens na cidade de Bissau e nas zonas rurais.

A crítica sociológica que podemos fazer a esse aspecto da sociedade guineense, controlada por essa lógica, é que ela nega o diálogo entre gerações, de forma aberta e relacional. Mais que isso, negam-se os meios para as transformações e inovações abertas - open innovations - de uma ideia distinta de juventude, vista estrategicamente para manter os mais jovens em seu devido lugar, por serem considerados como um grupo imaturo, cujo amadurecimento é de difícil precisão temporal. A dificuldade de comunicação e aceitação geracional induz à "fuga de cérebros" - brain drain - para sociedades mais abertas e plurais, nas quais existe maior circulação de ideias e interpelação na esfera pública.

Apesar dos desafios da desigualdade, que não são poucos, os fidjus dibideras primam pela qualidade, produzem a sua tecnologia, a sua literatura, o seu cinema e a sua arte. Por isso, procuram se comunicar com o mundo para aumentar as suas capacidades, a partir de uma visão universalista, mas sempre com a consciência 
de suas trajetórias de lutas, de culturas e de histórias africanas, sobretudo em seus contextos universitários.

Sintomas atuais dessa transformação geracional e societal, ainda em construção, podem ser observados na vida cotidiana das bideras guineenses, em todos os níveis, na Guiné e em suas diásporas. Cada vez mais, há fidjus dibideras e dibideros guineenses autônomos, intelectualmente participativos nas dinâmicas locais e diaspóricas de transformação social, projetando um novo ponto nodal, uma nova prática articulatória de imagem da Guiné-Bissau no mundo.

Por meio de seus esforços, as bideras e os bideros empregam, de modo cada vez mais acentuado, na formação dos filhos, que, hoje, assumem funções de destaque no funcionalismo público, em empresas privadas e em docência em universidades, como escritores, professores e artistas.

\section{Fidju dibidera como bolanha}

Há sinais positivos, ainda que insuficientes e contingentes, que, se conjugadas as sinergias na Guiné e em suas diferentes diásporas, poderão potencializar grandes reformações. Nós, fidjus dibideras, somos sujeitos que não nos damos por vencidos em nossas lutas por direito a ter direitos para a construção de uma nova ourique (nova bolanha) ${ }^{9}$ em movimento. Tão variada e rica, a bolanha é a voz e a presença literária de fidjus dibideras no mundo artístico e intelectual, em conciliação com a sua trajetória, cidadania, conhecimento crítico e luta pela autônoma para atingir seus objetivos.

Somos como uma bolanha, de cujos arados cultivam e desbravam os caminhos dos sonhos, das transformações de vidas em nossas vidas, revolvendo a nossa terra com seis arados em harmonia: o de solidariedade, o do respeito à diferença, o do reconhecimento, o do pluralismo de grupos socio étnicos e sociorreligiosos, o da literatura-mundo, a partir de Guiné-Bissau e de suas diásporas, e o das variantes linguísticas e literárias diversas, conectadas transnacionalmente.

9 Bolanha é um vasto terreno fértil, geralmente usado para o cultivo de arroz. Ele é composto da divisão da terra produtiva em filas que sustentam o cultivo e é dessa divisão que surge ourique. 
O maior desafio para uma mudança estrutural reside em criar sinergias nacionais e diaspóricas que potencializam novos conceitos, novas antologias de mudança, sem hierarquias e sem exclusões, como as bolanhas, pois os fidjus dibideras são arados de luta, sementeira da literatura e de cultura.

\section{REFERÊNCIAS}

ANDERSON, B. Comunidades imaginadas: reflexões sobre a origem e a difusão do nacionalismo. Tradução Denise Bottman. São Paulo: Companhias das Letras, 2008.

AUGEL, M. P. O desafio do escombro: nação, identidade e póscolonialismo na literatura da Guiné-Bissau. Rio de Janeiro: Garamond, 2007.

CAMARÁ, S. T. Lumo - Estatuto, funcionamento e organizações dos Mercados Periódicos na Guiné-Bissau: estudo de no lumo de Mafanco. 2011. Dissertação (Mestrado em Sociologia) - Departamento de Sociologia, Instituto Universitário de Lisboa. Lisboa: ISCTE-IUL, 2011.

CARREIRA, A. Panaria cabo-verdiana e guineense: aspectos históricos e sócio-econômicos. Praia: ICL, 1983.

FURTADO, A. Administração e Gestão da Educação na Guiné-Bissau: incoerências e descontinuidades. 2005. Tese (Doutorado em Educação) Departamento de Ciências da Educação, Universidade de Aveiro. Aveiro: UA \DCE, 2005.

SANI, Q.; OLIVEIRA, R. M. Educação superior e desenvolvimento na GuinéBissau: contribuições, limites e desafios. Revista Pedagógica, Chapecó, v. 16, n. 33, p. 127 - 152, 2014.

SUCUMA, A. Estado e ensino superior na Guiné-Bissau 1974 - 2008. 2013. Dissertação (Mestrado em Ciência Política) - Programa de Pósgraduação em Ciência Política, Centro de Filosofia e Ciências Humanas, Universidade Federal de Pernambuco, 2013.

TEIXEIRA, R. D. Transição democrática e modelos de democracia. Tensões Mundiais, Fortaleza, v. 11, n. 21, p. 199-223, jul./dez. 2015.

Conhecimento e pós-colonialismo na literatura-global de fidjus dibideras. BUALA, Lisboa, 27 jul. 2019. Disponível em: https://www.buala. org/pt/a-ler/conhecimento-e-pos-colonialismo-na-literatura-global-dosescritores-guineenses-fidjus-dibidera. Acesso em: 30 jul. 2020. 